\title{
An examination of autism spectrum traits in adolescents with anorexia nervosa and their parents
}

\author{
Charlotte Rhind $^{1 *}$, Elena Bonfioli ${ }^{2}$, Rebecca Hibbs ${ }^{1}$, Elizabeth Goddard ${ }^{1}$, Pamela Macdonald ${ }^{1}$, Simon Gowers ${ }^{3}$, \\ Ulrike Schmidt ${ }^{1}$, Kate Tchanturia ${ }^{1,4}$, Nadia Micali ${ }^{5+}$ and Janet Treasure ${ }^{1+}$
}

\begin{abstract}
Background: There may be a link between anorexia nervosa and autism spectrum disorders. The aims of this study were to examine whether adolescents with anorexia nervosa have autism spectrum and/or obsessive-compulsive traits, how many would meet diagnostic criteria for autism spectrum disorder, and whether these traits are shared by parents.

Methods: A total of 150 adolescents receiving outpatient treatment for anorexia nervosa or subthreshold anorexia nervosa and their parents completed the autism spectrum disorder and eating disorder sections of the Development and Well-being Assessment. Patients also completed the Children Yale-Brown Obsessive-Compulsive Scale and other measures of psychiatric morbidity, and parents completed the short Autism Quotient and Obsessive-Compulsive Inventory Revised.

Results: Adolescents with anorexia nervosa had a below average social aptitude (19\% below cut-off) and high levels of peer relationship problems (39\% above cut-off) and obsessive-compulsive symptoms (56\% above cut-off). Six cases (4\%, all females) were assigned a possible $(n=5)$ or definite $(n=1)$ diagnosis of autism spectrum disorder. Parental levels of autism spectrum and obsessive-compulsive traits were within the normal range.

Conclusions: This study suggests that adolescents with anorexia nervosa have elevated levels of autism spectrum traits, obsessive-compulsive symptoms, and a small proportion fulfil diagnostic criteria for a probable autism spectrum disorder. These traits did not appear to be familial. This comorbidity has been associated with a poorer prognosis. Therefore, adaptation of treatment for this subgroup may be warranted.
\end{abstract}

Trial registration: Controlled-trials.com: ISRCTN83003225. Registered on 29 September 2011.

Keywords: Anorexia nervosa, Eating disorder, Autism spectrum disorder, Obsessive-compulsive disorder, Traits, Social aptitude, Adolescents, Parents, Development, Well-being assessment

\section{Background}

An association between low empathy during development and the later development of an eating disorder (ED) was suggested by Gillberg in 1992 [1]. He proposed that individuals with autism spectrum disorders (ASD) and those with anorexia nervosa (AN) may share traits, some of

\footnotetext{
* Correspondence: charlotte.c.rhind@kcl.ac.uk

${ }^{\dagger}$ Equal contributors

'King's College London, Institute of Psychiatry, Psychology and Neuroscience, Department of Psychological Medicine, Section of Eating Disorders, PO59 103 Denmark Hill, London SE5 8AF, UK

Full list of author information is available at the end of the article
}

which might be familial [1]. Evidence summarized in recent reviews provides support for this hypothesis, suggesting that there may be a shared liability between AN and ASD [2-4]. For example, both disorders have a similar profile of neuropsychological function (problems with set shifting, central coherence, and social cognition) and behavioral traits such as social problems, and obsessive-compulsive features such as rigidity and attention to detail [2-4], although the neuropsychological profile of adolescents with AN is less clear (for an example see Lang et al. [5]).

Several studies have used the autism quotient (AQ), a self-report measure of autism spectrum traits, in people 
with $\mathrm{AN}$ and have found higher than normal scores [6,7]. A study using the AQ and measures of systemizing and empathizing traits concluded that over $40 \%$ of adolescents with AN fulfilled the criteria for the broad autistic phenotype [8]. Another study found that $26 \%$ of adults with AN scored above the cut-off score on the short AQ [9]. In a large population study using parent report, $23 \%$ of children with restrictive eating problems also screened positive for ASD [10]. These studies suggest that there are shared traits between AN and ASD.

One problem in establishing the association between these conditions is that it can be difficult to make the diagnosis of ASD in women. Their clinical presentation differs from that typically seen in men, as summarized in a recent review [11]. Parents endorse different items for girls with ASD (such as 'avoids demands', 'very determined', and 'careless with physical appearance and dress') using a scale adapted to capture the female phenotype of ASD [12]. Furthermore, females present with more lifetime sensory problems [13]. It is thought that females with autism spectrum traits may be more likely to focus on eating or shape and weight issues as a topic of special interest.

People with EDs and their family members have higher levels of obsessive-compulsive personality traits $[14,15]$. Behavioral traits, such as attention to detail and rigidity, are part of this personality profile and are common to those with EDs and ASD [2-4]. For example, the perceptual style of weak central coherence characterized by precedence for detail processing and/or difficulties with integrating global information is present in all three disorders [16-18]. A compulsivity phenotype may account for some of the common variance between these co-morbid conditions [19].

The aims of this study were to examine this dimensional approach to diagnosis by assessing whether adolescents with AN have autism spectrum and obsessive-compulsive traits, to establish the prevalence of ASD amongst this patient group, and whether these traits are shared by parents. It was hypothesized that (1) adolescents with AN would have higher levels of autism spectrum (poorer social aptitude skills and greater peer difficulties) and obsessive-compulsive traits, relative to population norms; (2) a higher proportion of adolescents with AN would fulfil diagnostic criteria for ASD than female healthy population norms, using the Development And Well-being Assessment (DAWBA) [20]; and (3) parents of adolescents with AN would have higher levels of autism spectrum and obsessive-compulsive traits, relative to population norms.

\section{Methods}

Participants

Adolescents newly referred for outpatient treatment with a primary diagnosis of AN or ED Not Otherwise Specified
AN subtype (EDNOS-AN) and their parents completed a battery of assessments as part of a randomized controlled trial (Experienced Carers Helping Others (ECHO, trial registration: ISRCTN83003225)). Participants were recruited from 38 National Health Service (NHS) England outpatient services, providing an ecologically relevant sample representative of current United Kingdom practice. ED diagnoses were made by a clinician at the local recruitment site, according to the Diagnostic and Statistical Manual of Mental Disorders, 4th Edition (DSM-IV) criteria [21]. An age range of 13 to 21 years was chosen to represent an adolescent sample; up until brain development comes to completion (early twenties) [22] and usually whilst in full-time education. This is also consistent with previous similar adolescent trials [23]. Main ethics approval was granted by the Northwick Park Hospital Ethics Committee (approval number: 11/H0724/4) and site-specific ethics and governance approval granted on all participating sites (please see Acknowledgements). Written assent was collected for all patients and informed consent from their parents or guardians and all other participating carers was collected prior to entering the study in accordance with ethical guidelines. The methodology is described in detail elsewhere [24]. Only participants who completed the DAWBA and their parents were included in the present study. The final sample consisted of 150 adolescents (92\% of total recruited) receiving treatment for AN $(75 \%)$ or EDNOS-AN $(25 \%)$ and their parents $(n=207)$. No differences were found between the participants included in the present study and the 163 patients and 224 parents recruited on clinical (body mass index (BMI), lowest BMI, and illness duration) and demographic variables (gender, employment, and marital status) with the exception of parental age which was greater in the sample included (data not shown).

\section{Patient measures}

Standard demographic and clinical information were completed as self-report by patients (validated by clinicians) and their parents.

\section{The developmental and well-being assessment}

The DAWBA [20] is a well-validated and extensively used measure in epidemiological studies that is designed to generate a DSM-IV and an International Statistical Classification of Diseases and Related Health Problems (ICD-10) psychiatric diagnosis for childhood and adolescent psychiatric disorders. The ASD section is used as a diagnostic measure in population-based prevalence studies of ASD $[25,26]$. In the present study, parents (informants) and patients (self-report) complete the ASD and ED sections of the computerized DAWBA which includes interview questions (each with screening questions) and skip rules. 
Parents report on their child's development (language, routines, play, and social ability) and complete the Social Aptitudes Scale (SAS) [27], both designed to capture 'traits' rather than 'state' effects. The SAS is designed to tap the sorts of social aptitudes that require a good ability to read social and emotional cues rapidly in complex situations in order to guide socially skilled behaviour. Parents rate their child from 'a lot worse than average' to 'a lot better than average', relative to other children of the same age, across 10 items. Low scores index a substantially raised risk of ASDs. The SAS has been well-validated and demonstrated good psychometric properties: data from a large epidemiological study of young people in the United Kingdom produced a mean score of 24.57 ( $S D=6.26$, $\mathrm{n}=7768$ ) with higher scores for females (mean $=25.33$, $\mathrm{SD}=6.14, \mathrm{n}=3764)$. A cut-off score of 16 or less is associated with good screening properties for the diagnosis of ASD [27]. Age-transformed aptitude scores with a mean of 50 and standard deviation of 10 have been developed [27]. Cronbach's $\alpha$ coefficient $(\alpha)$ for responses to the SAS in the present study was 0.90 .

The DAWBA generates six diagnostic probability bands (ranging from $<0.1$ to $>70 \%$ likelihood) and a summary of structured and open-ended interview data, triangulated across informants by a trained experienced clinician (NM), who assigned a diagnosis ('yes', 'possible', or 'no') according to DSM-IV and ICD-10 criteria.

Parents and the individuals themselves also completed the Strengths and Difficulties Questionnaire (SDQ) [28] which consists of 25 items that assess behaviour problems, hyperactivity, emotional symptoms, peer problems, and pro-social skills. The sum of the first four subscale scores forms a total difficulties score, with higher scores indicating greater difficulties. Ratings of child distress and the impact of difficulties on social capital form a total impact score. Social skills can be inferred from the pro-social and peer relationship subscales. Good psychometric properties are reported for the SDQ. Normative data from a large epidemiological study [29] are available online with cut-off points; specifically, peer difficulties scores of 0 to 2 may be classified as normal, a score of 3 as 'borderline', and scores of 4 to 10 as 'abnormal'. In the current study, Cronbach's $\alpha$ for responses to the SDQ symptom domains was 0.83 (informant) and 0.82 (self-report).

\section{The children's Yale-Brown obsessive-compulsive scale}

Obsessive-compulsive traits in patients were assessed using the self-report Children's Yale-Brown Obsessive-Compulsive Scale (CY-BOCS-SR) [30]. Higher scores indicate higher symptom severity (score range 0 to 40 ) and scores of 16 and over are used as a cut-off for clinically significant obsessive-compulsive disorder. Cronbach's $\alpha$ for responses to the CY-BOCS-SR in the current study was 0.71 .

\section{The short evaluation of eating disorders}

The Short Evaluation of EDs (SEED) [31] was completed by self-report to assess ED symptom severity. Responses are scored using an algorithm including weight and key symptoms and computed a total AN and Bulimia Nervosa $(\mathrm{BN})$ symptom severity index (score range 0 to 3; higher score indicating severity). Cronbach's $\alpha$ for the SEED in this study was 0.72 .

\section{Clinical impairment assessment 3.0}

Psychosocial impairments related to the ED features over the past 28 days were also assessed using the Clinical Impairment Assessment (CIA) [32]. A global score is calculated with higher scores indicating greater severity of impairment. Cronbach's $\alpha$ for the CIA in this study was 0.94 .

\section{The depression, stress and anxiety scale}

The Depression, Stress and Anxiety Scale (DASS-21) [33] was used as a self-report measure of current mood state. Cronbach's $\alpha$ for the DASS-21 was 0.94 .

\section{Parent measures}

\section{The short autism quotient}

Autism spectrum traits in parents were assessed using the Short Autism Quotient (AQ-10) [34]. Healthy adults produced a mean score of $2.77(\mathrm{SD}=2.00)$ and a cut-off point of 6 is indicative of ASD [34]. Cronbach's $\alpha$ for the AQ-10 in this study was 0.56 .

\section{The obsessive-compulsive inventory}

Obsessive-compulsive traits in parents were measured using the Obsessive-Compulsive Inventory (OCI-R) [35]. A cut-off point of 21 is indicative of clinically significant obsessive-compulsive disorder. Cronbach's $\alpha$ for the OCI-R in this study was 0.88 .

\section{Data analysis}

Data were analyzed using IBM SPSS Statistics for Windows, Version 21.0: Armonk, New York. Descriptive statistics summarized means and standard deviations for patient and parent scores on all measures. Independent samples t-tests were used for group comparisons: social aptitude scores in present study sample versus population mean; patients who did versus did not receive a diagnosis for ASD; and mothers versus fathers. Cohen's d was used to calculate effect sizes. Spearman's correlations were used to measure associations between patients autism spectrum and obsessive-compulsive traits, and their current ED clinical characteristics, and parental traits, applying a Bonferronicorrected $\alpha$ (0.05 out of $13, \alpha=0.004)$ to correct for multiple comparisons. 


\section{Results}

The patient sample was 91\% female, 96\% Caucasian, and 91\% were living with their parents. The age ranged from 13 to 21 years $($ mean $=16.90, \mathrm{SD}=2.13)$ and $83.6 \%$ were within three years of illness onset. The majority of patients (69\%) had received no prior treatment for their ED. One patient in the sample reported having received a diagnosis of ASD. Other clinical information is displayed in Table 1 . The mother (mean age $=48$ years, $\mathrm{SD}=4.82$ ) was involved in the study for $95 \%$ of patients and the father for $42 \%$ (mean age $=51$ years, $\mathrm{SD}=5.06$ ).

\section{Psychometric assessment of adolescents with anorexia nervosa}

Social aptitude scores $($ mean $=22.87, \mathrm{SD}=8.16)$ were lower than the healthy population norm (see legend, Table 2; $\mathrm{t}=3.03, p=0.002, \mathrm{~d}=-0.23)$, particularly for females ( mean $=22.71, \mathrm{SD}=8.35 ; \mathrm{t}=4.51, p<0.001, \mathrm{~d}=-0.36$ ). Scores fell within the clinically significant range for $18.8 \%$ of patients. They were not significantly correlated with clinical characteristics (BMI, illness duration, AN symptom severity, BN symptom severity, ED clinical impairment, depression, anxiety, or stress scores; data not shown).

For both categories of rater (informant (I) and self-report (SR)) completing the SDQ, the highest levels of difficulties relative to norms were in the emotional (I: $d=2.07$, SR: $d=1.73$ ) and peer domains (I: $d=0.76, S R: d=0.94$ ).
Peer difficulties were 'abnormal' for $38.5 \%$ of patients, and 'borderline' for a further $12.9 \%$. Informants only reported lower than average levels of pro-social skills (I: $\mathrm{d}=-0.75$, SR: $d=-0.05$ ), particularly for females (I: $d=-0.89$, SR: $d=-0.37)$. The individuals themselves reported higher than average levels of hyperactivity $(S R: d=0.62)$ and a smaller effect was reported by informants (I: $d=0.32$ ). Informants rated a moderate level of conduct problems (I: $d=0.52$, SR: $d=0.05$ ).

Scores for obsessive-compulsive symptoms (CYBOCS-SR) were within the clinically significant range for obsessive-compulsive disorder in $56.4 \%$ of the sample. Scores were significantly correlated with duration of illness (Spearman's correlation coefficient $\left(r_{\mathrm{s}}\right)=0.26, p<0.001$ ), BN symptom severity $\left(r_{\mathrm{s}}=0.34, p<0.001\right)$, ED clinical impairment $\left(r_{\mathrm{s}}=0.51, p<0.001\right)$, depression $\left(r_{\mathrm{s}}=0.42, p<0.001\right)$ and anxiety $\left(r_{\mathrm{s}}=0.45, p<0.001\right)$, but not with BMI, lowest BMI or AN symptom severity.

\section{Diagnostic assessment of autism spectrum disorder}

Compared with normative data, more AN females were assigned to the higher diagnostic probability bands of the DAWBA (10.9\% AN versus $1.2 \%$ norms at level 2 (>3\% likelihood of ASD) and 2.5\% AN versus $0.3 \%$ norms at level 3 (>15\% likelihood of ASD)).

Six individuals (4\%, all female) were assigned a possible $(n=5)$ or definite $(n=1)$ diagnosis of ASD by the clinical

Table 1 Sociodemographic and clinical characteristics

\begin{tabular}{|c|c|c|c|c|}
\hline & $\begin{array}{l}\text { Females }(\mathrm{N}=137) \\
\text { Mean }(\mathrm{SD}, \text { range }) / \mathrm{n} \\
(\text { valid \%) }\end{array}$ & $\begin{array}{l}\text { Males }(\mathrm{N}=13) \\
\text { Mean }(\mathrm{SD}, \text { range }) / \mathrm{n} \\
(\text { valid \%) }\end{array}$ & $\begin{array}{l}\text { Total }(\mathrm{N}=150) \\
\text { Mean }(\mathrm{SD}, \text { range }) / \mathrm{n} \\
(\text { valid \%) }\end{array}$ & $\begin{array}{l}\text { ASD subset }(\mathrm{N}=6, \text { all females) } \\
\text { Mean }(\mathrm{SD}, \text { range)/n } \\
\text { (valid } \%)\end{array}$ \\
\hline Age (years) & $16.86(2.11,12.42-21.57)$ & $17.31(2.37,13.20-21.53)$ & $16.90(2.13,12.42-21.57)$ & $17.09(1.95,15.27-20.21)$ \\
\hline Illness duration (months) & $22.83(23.60,2.00-110.00)$ & $20.58(11.26,4.00-39.00)$ & $22.64(22.79,2.00-110.00)$ & $19.00(15.45,4.00-49.00)$ \\
\hline BMI & $16.81(2.17,12.38-24.20)$ & $17.16(2.44,13.00-21.60)$ & $16.84(2.19,12.38-24.20)$ & $16.45(2.25,14.30-20.50)$ \\
\hline Weight-for-height (\%) ${ }^{a}$ & $82.50(11.58,55.07-122.97)$ & $84.77(15.78,65.19-106.14)$ & $82.65(11.82,55.07-122.97)$ & $79.93(10.94,65.98-92.70)$ \\
\hline Lowest BMI & $15.45(2.29,11.40-23.60)$ & $15.22(2.63,12.00-18.30)$ & $15.43(2.30,11.40-23.60)$ & $14.56(1.20,13.10-16.40)$ \\
\hline \multicolumn{5}{|l|}{ Previous hospital admission } \\
\hline 0 & $120(92.3 \%)$ & $11(91.7 \%)$ & $131(92.3 \%)$ & $5(100 \%)$ \\
\hline 1 & $9(6.9 \%)$ & $1(8.3 \%)$ & $10(7.0 \%)$ & 0 \\
\hline 2 & $1(0.8 \%)$ & 0 & $1(0.7 \%)$ & 0 \\
\hline Missing & $7(5.1 \%)$ & $1(7.7 \%)$ & $8(5.3 \%)$ & $1(16.7 \%)$ \\
\hline \multicolumn{5}{|l|}{ DAWBA ED diagnosis ${ }^{b}$} \\
\hline AN & $82(59.9 \%)$ & $5(38.5 \%)$ & 87 (58.0\%) & $3(50.0 \%)$ \\
\hline EDNOS & 49 (35.8\%) & $7(53.8 \%)$ & $56(37.3 \%)$ & $3(50.0 \%)$ \\
\hline $\mathrm{BN}$ & $1(0.7 \%)$ & 0 & $1(0.7 \%)$ & 0 \\
\hline Possible & $1(0.7 \%)$ & 0 & $1(0.7 \%)$ & 0 \\
\hline No & $4(2.9 \%)$ & $1(7.7 \%)$ & $5(3.3 \%)$ & 0 \\
\hline
\end{tabular}

${ }^{a}$ Age standardized weight-for-height (participants aged $<20$ years $(n=126)$ only are reported), according to Great Ormond Street Hospital for Children criteria. ${ }^{b}$ Clinical rating using the DAWBA (DSM-IV and ICD-10 criteria).

Abbreviations: AN, Anorexia Nervosa; ASD, Autism spectrum disorder; BMI, Body Mass Index; BN, Bulimia Nervosa; DAWBA, Development and Well-being Assessment; ED, Eating Disorder; EDNOS, Eating Disorder Not Otherwise Specified. 
Table 2 Patient psychiatric symptomatology and comorbidity

\begin{tabular}{|c|c|c|c|c|}
\hline & $\begin{array}{l}\text { All females }(N=137) \\
\text { Mean }(S D)\end{array}$ & $\begin{array}{l}\text { All males }(\mathrm{N}=13) \\
\text { Mean }(\mathrm{SD})\end{array}$ & $\begin{array}{l}\text { Total }(N=150) \\
\text { Mean }(S D)\end{array}$ & $\begin{array}{l}\text { ASD subset ( } N=6 \text {, all females) } \\
\text { Mean (SD) }\end{array}$ \\
\hline CY-BOCS total & $16.95(8.79)$ & $13.58(8.34)$ & $16.63(8.77)$ & $16.00(9.82)$ \\
\hline$S A S^{a}$ & $22.71(8.35)$ & $24.70(5.29)$ & $22.87(8.16)$ & $7.00(2.37)$ \\
\hline SAS T-score ${ }^{a}$ & $45.50(12.01)$ & $48.00(7.23)$ & $45.70(11.69)$ & $23.50(2.34)$ \\
\hline \multicolumn{5}{|l|}{ SDQ Peer problems ${ }^{\mathrm{b}}$} \\
\hline Self-report & $3.14(2.05)$ & $3.00(1.55)$ & $3.13(2.01)$ & $4.60(2.88)$ \\
\hline Informant & $2.95(2.19)$ & $3.36(2.16)$ & $2.98(2.18)$ & $5.67(1.75)$ \\
\hline \multicolumn{5}{|l|}{ SDQ Pro-social skills ${ }^{c}$} \\
\hline Self-report & $7.93(1.70)$ & $7.82(1.66)$ & $7.92(1.69)$ & $7.20(0.84)$ \\
\hline Informant & $7.08(2.29)$ & $7.64(2.20)$ & $7.13(2.28)$ & $4.50(1.98)$ \\
\hline \multicolumn{5}{|l|}{ SDQ Emotional } \\
\hline Self-report & $6.63(2.35)$ & $6.91(2.34)$ & $6.65(2.34)$ & $6.40(2.97)$ \\
\hline Informant & $6.59(2.45)$ & $5.82(2.27)$ & $6.52(2.44)$ & $8.00(1.10)$ \\
\hline \multicolumn{5}{|l|}{ SDQ Conduct } \\
\hline Self-report & $2.34(1.70)$ & $1.73(1.35)$ & $2.29(1.68)$ & $2.80(1.64)$ \\
\hline Informant & $2.42(1.74)$ & $2.27(2.37)$ & $2.41(1.79)$ & $3.00(2.37)$ \\
\hline \multicolumn{5}{|l|}{ SDQ Hyperactivity } \\
\hline Self-report & $5.14(2.29)$ & $5.27(1.95)$ & $5.16(2.16)$ & $5.80(2.39)$ \\
\hline Informant & $4.00(2.30)$ & $3.64(1.86)$ & $3.97(2.26)$ & $4.67(2.51)$ \\
\hline \multicolumn{5}{|l|}{ SDQ Total difficulties } \\
\hline Self-report & $17.24(6.17)$ & $16.91(4.66)$ & $17.22(6.04)$ & $19.60(7.13)$ \\
\hline Informant & $15.96(6.48)$ & $15.09(6.28)$ & $15.89(6.44)$ & $21.33(5.50)$ \\
\hline \multicolumn{5}{|l|}{ SDQ Impact } \\
\hline Self-report & $4.40(3.36)$ & $3.73(4.65)$ & $4.34(3.46)$ & $4.40(3.65)$ \\
\hline Informant & 3.99 (3.14) & $3.82(3.25)$ & $3.98(3.14)$ & $7.17(0.75)$ \\
\hline \multicolumn{5}{|c|}{ ASD probability band $d^{d, e}$} \\
\hline$<0.1 \%$ & 102 (85.7\%) & 10 (91.9\%) & 112 (86.2\%) & 1 (16.7\%) \\
\hline Approx. 3\% & 13 (10.9\%) & 1 (9.1\%) & $14(10.8 \%)$ & $4(66.7 \%)$ \\
\hline Approx. 15\% & $3(2.5 \%)$ & 0 & $3(2.3 \%)$ & $1(16.7 \%)$ \\
\hline Approx. 50\% & $1(0.8 \%)$ & 0 & $1(0.8 \%)$ & 0 \\
\hline Missing & 18 (13.1\%) & $2(15.4 \%)$ & $20(13.3 \%)$ & 0 \\
\hline \multicolumn{5}{|l|}{ Diagnosis ASD } \\
\hline Possible & $5(3.6 \%)$ & 0 & $5(3.3 \%)$ & $5(83.3 \%)$ \\
\hline Yes & $1(0.7 \%)$ & 0 & $1(0.7 \%)$ & 1 (16.7\%) \\
\hline
\end{tabular}

aLower scores indicate poor social aptitude (cut-off score 16 or less). British (age 11 to 14 years) healthy population mean $=24.57$ (SD $=6.26$ ), females only mean $=25.33(S D=6.14)$, males only mean $=23.81(S D=6.38)$. SAS Age-Transformed-score mean $=50(S D=10)[27]$.

${ }^{b}$ British (age 11 to 14 years) healthy population informant-rated mean $=1.5(S D=1.7)$, self-report mean $=1.5(S D=1.4)[29]$.

${ }^{c}$ British (age 11 to 14 years) healthy population informant-rated mean $=8.6(S D=1.6)$, self-report mean $=8.0(S D=1.7)[29]$.

${ }^{\mathrm{d} B r i t i s h}$ (age 11 to 14 years) healthy population females $(\mathrm{F})$ and males $(\mathrm{M})$ selecting those with no intellectual disability $A S D$ band $<0.1 \%=98.3 \%(F), 95.7 \%(M) ;$

ASD band approximately $3 \%=1.2 \%(F), 2.1 \%(M)$; ASD band approximately $15 \%=0.3 \%(F), 1.4 \%(M)$; ASD band approximately $50 \%=0.2 \%(F), 0.4 \%(M)$.

${ }^{\mathrm{V}}$ alid percentages presented.

${ }^{\text {e}}$ Clinical rating using the DAWBA (DSM-IV and ICD-10 criteria).

Abbreviations: SAS, Social Aptitude Scale; SDQ, Strengths and Difficulties Questionnaire; ASD, Autism Spectrum Disorder.

rater. Clinical and psychometric features of these cases are displayed in Table 2. Informant-rated scores for total difficulties $(\mathrm{d}=0.95)$ and impact $(\mathrm{d}=1.47)$ were higher for this subgroup.
Parental autism spectrum and obsessive-compulsive traits Levels of autism spectrum and obsessive-compulsive traits in parents of adolescents with AN were within the normal range (Table 3$)$. Only $2.2 \%$ of parents $(n=2$ 
Table 3 Parental traits

\begin{tabular}{cccccccc}
\hline & \multicolumn{3}{c}{ All parents } & & \multicolumn{3}{c}{ Parents of ASD subset only } \\
\cline { 2 - 3 } & Mothers $(\mathbf{N}=\mathbf{1 4 3})$ & Fathers $(\mathbf{N}=\mathbf{6 4})$ & Total $(\mathbf{N}=\mathbf{2 0 7})$ & & Mothers (N=6) & Fathers (N=6) & Total (N= 12) \\
\hline AQ-10 & $1.95(1.52)$ & $2.81(1.84)$ & $2.20(1.66)$ & & $1.80(1.10)$ & $2.67(1.53)$ & $2.13(1.25)$ \\
OCl-R & $8.85(9.06)$ & $7.50(7.23)$ & $8.47(8.59)$ & & $14.00(9.43)$ & $6.33(4.04)$ & $11.13(8.44)$ \\
\hline
\end{tabular}

Means and SD displayed; Abbreviations: ASD, Autism spectrum disorder; AQ-10, Autism Quotient; OCI-R, the Obsessive-Compulsive Inventory Revised.

(3.1\%) fathers, $\mathrm{n}=2$ (1.4\%) mothers) scored within the clinically significant range suggestive of ASD. Fathers produced higher scores than mothers $(\mathrm{t}=-3.32, p=0.001$, $\mathrm{d}=0.51$ ). Scores for obsessive-compulsive traits (OCI-R) were within the clinically significant range for $7.9 \%$ of parents.

There were no significant differences in autism spectrum traits (AQ-10) between parents of those assigned an ASD diagnosis compared with those who were not.

\section{Correlations between autism spectrum and obsessive-compulsive traits}

Table 4 presents the correlations between autism spectrum (social aptitude and SDQ peer problems, and pro-social behaviors) and obsessive-compulsive traits (CY-BOCS-SR) in patients and in mothers and fathers (AQ-10 and OCI-R). Patient autism spectrum traits (social aptitude, peer difficulties, and pro-social behaviors) and obsessive-compulsive traits were not significantly correlated. Parental autism spectrum (AQ-10) and obsessive-compulsive traits (OCI-R) were significantly correlated for mothers only. Parental traits were not correlated with autism spectrum or obsessive-compulsive scores in patients.

\section{Discussion}

The first aim of this study was to examine whether adolescents with AN have traits suggestive of ASD. We confirmed our first hypothesis in that we found that poor social aptitude skills and peer difficulties were more prevalent in the $\mathrm{AN}$ patients than in healthy population norms. We also found high co-morbid obsessive-compulsive traits in the patient group. We found that six (4\%) patients met the diagnostic criteria for a possible or definite ASD. However, we failed to confirm our hypothesis that the parents of the patient group would have higher than normal levels of autism spectrum and obsessive-compulsive traits.

The prevalence of autism spectrum traits (low social aptitude (18.8\%) and peer difficulties) is similar to the approximate $20 \%$ of the cohort of adolescent cases of AN who were thought to have social communication difficulties reported by Gillberg [1] and the $23 \%$ of children with restrictive eating problems who also screened positive for ASD [10]. It is lower than the $40 \%$ of adolescents fulfilling the Baron Cohen's criteria for the broad autistic phenotype [8]. The different populations, screening, and diagnostic procedures used in these studies may account for this variance.

The prevalence of diagnostically defined cases (4\%) is lower than the proportion (23\%) of adult patients with a severe and enduring ED who were considered to have ASD [36]. In part this may relate to the use of the DAWBA as a developmentally based diagnostic measure; however, given the poor prognosis of this group [37], it might be expected that a greater proportion of cases with ASD will be found in cohorts with a severe and enduring illness.

The six individuals with possible and definite ASD had a similar clinical profile to the group as a whole. However, informant ratings suggested that this subgroup had greater overall difficulties. However, given the small number, group comparisons are underpowered and these descriptors are therefore unreliable.

The problems in social functioning are consistent with the previous literature. Patients with EDs particularly those with AN retrospectively report social difficulties in childhood [38]. In a longitudinal study, social problems at age eight were strongly predictive of ED onset at age 14 [39]. Furthermore, a recent systematic review has documented the wide range of difficulties within the social cognition domain [40]. Although there may be 'state' effects of AN on neuropsychological functioning, the lack of association between social aptitude and current AN features is more indicative of a trait level of disturbance. The level of other forms of comorbidity in this group (obsessive-compulsive disorder traits, negative affect and some Attention Deficit/ Hyperactivity Disorder symptoms) is similar to that in the literature [41-43].

We did not find that the parents of patients with EDs had high levels of autism spectrum traits themselves. Parents of people with ASD have been found to have high autism quotient scores $[44,45]$, mainly in the social and communication domains $[46,47]$, suggesting that there is a broad familial ASD phenotype. However, this finding is less robust in mothers of people with ASD [48]. The small number of cases and the different instruments used makes the interpretation of possible cross-generational traits versus possible 'state' effects of AN difficult.

\section{Strengths and limitations}

One of the strengths of this study was the use of the DAWBA as an assessment measure that has been widely 
Table 4 Correlations between autism spectrum disorder and obsessive-compulsive disorder traits in female patients and their parents

\begin{tabular}{|c|c|c|c|c|c|c|c|c|c|c|c|c|c|}
\hline & \multicolumn{9}{|c|}{ Patient variables } & \multicolumn{4}{|c|}{ Parent variables } \\
\hline & 1 & 2 & 3 & 4 & 5 & 6 & 7 & 8 & 9 & 10 & 11 & 12 & 13 \\
\hline 1. Social aptitude & - & & & & & & & & & & & & \\
\hline 2. Peer problems ${ }^{a}$ & -0.27 & - & & & & & & & & & & & \\
\hline 3. Peer problems ${ }^{b}$ & $-0.40^{* *}$ & $0.60^{* *}$ & - & & & & & & & & & & \\
\hline 4. Pro-social skills ${ }^{a}$ & 0.17 & $-0.35^{* *}$ & -0.15 & - & & & & & & & & & \\
\hline 5. Pro-social skills ${ }^{b}$ & $0.58^{* *}$ & -0.18 & $-0.38^{* *}$ & 0.18 & - & & & & & & & & \\
\hline 6. Emotion difficulties ${ }^{a}$ & -0.19 & $0.38^{* *}$ & 0.27 & -0.17 & -0.09 & - & & & & & & & \\
\hline 7. Emotions difficulties ${ }^{b}$ & $-0.29^{*}$ & $0.23^{*}$ & $0.53^{* *}$ & 0.03 & $-0.32^{* *}$ & $0.34^{* *}$ & - & & & & & & \\
\hline 8. CY-BOCS-SR & -0.05 & 0.16 & $0.20^{*}$ & -0.13 & -0.09 & $0.32^{*}$ & 0.18 & - & & & & & \\
\hline 9. ASD Diagnostic Band & $-0.45^{* *}$ & $0.31^{*}$ & $0.40^{* *}$ & -0.13 & $-0.27^{*}$ & $0.32^{*}$ & $0.32^{* *}$ & 0.19 & - & & & & \\
\hline 10. Mother AQ-10 & -0.11 & 0.15 & 0.20 & 0.03 & -0.01 & 0.18 & 0.05 & 0.06 & 0.19 & - & & & \\
\hline 11. Father AQ-10 & -0.13 & 0.32 & 0.33 & 0.22 & -0.11 & -0.06 & 0.17 & -0.14 & 0.09 & -0.23 & - & & \\
\hline 12. Mother OCl-R & -0.20 & 0.19 & 0.21 & -0.14 & -0.09 & 0.15 & 0.24 & 0.07 & 0.24 & $0.32^{* *}$ & 0.14 & - & \\
\hline 13. Father OCI-R & -0.35 & 0.25 & 0.29 & 0.05 & -0.39 & 0.13 & 0.26 & -0.02 & -0.01 & 0.04 & 0.31 & -0.01 & - \\
\hline
\end{tabular}

Spearman's correlation coefficient $\left(r_{s}\right)$ applying a Bonferroni-corrected alpha $(a=0.004)$; Abbreviations: AQ-10, Autism Quotient; ASD, Autism spectrum disorder; CY-BOCS-SR, Children's Yale-Brown Obsessions and Compulsions Symptom Scale Revised; OCD, Obsessive-compulsive disorder; OCI-R, the Obsessive-Compulsive Inventory Revised.

${ }^{\text {a S}}$ Strength and Difficulties Questionnaire by self-report.

${ }^{\mathrm{b}}$ Strength and Difficulties Questionnaire by informant. ${ }^{*} p<0.003,{ }^{* *} p<0.001$.

employed in epidemiological studies of child and adolescent psychiatry, with healthy population norms available for comparison. Furthermore, because the DAWBA is framed developmentally and collects self-report and informant perspectives, it is less reliant on current symptoms or impairment ('state' effects of AN). Another strength of this study is the inclusion of both child and parent data. Nevertheless, several limitations must be noted; we used instruments that measured obsessive-compulsive disorder behaviors and it would have been preferable to have included instruments to measure traits associated with compulsivity, an over-controlled temperament, and obsessive-compulsive personality. Additionally, the internal consistency of the AQ-10 was poor and caution must be taken when interpreting these results. It would have been preferable to have also screened the participants themselves with the AQ-10. The possibility that the DAWBA is less diagnostically sensitive than an in-depth face-to-face clinician examination must also be considered. Given that the DAWBA assigned fewer $\mathrm{AN}$ and overall ED diagnoses in a sample of clinically diagnosed and treatment-seeking AN and EDNOS-AN patients, it is possible that the DAWBA provides a relatively conservative diagnostic tool. Furthermore, the patient previously diagnosed with ASD prior to entering the study was assigned a 'probable' (rather than 'definite') diagnosis using the DAWBA in the present study. It is therefore possible that the prevalence of ASD in AN may be higher than that reported in this study. Finally, the data presented do not represent all treatment-seeking patients, but only the group who consented to be involved in a study that involves their parents. It is possible that the sample is therefore biased towards patients with parents who were more actively involved in their child's care.

\section{Clinical implications}

We have found that a small number of adolescent AN cases are possibly comorbid with ASD. We have also found evidence of transdiagnostic traits such as social communication and emotional problems. These may be associated with ASD, the over-controlled temperament [49], and obsessive-compulsive personality [50] in adolescents with EDs. Treatment adaptations to target these difficulties may be beneficial.

\section{Conclusions}

Approximately one fifth of adolescents with AN have obsessive-compulsive traits and problems in peer relationships and social functioning. A much smaller proportion (4\%) fulfil the diagnostic criteria for a probable ASD. It will be of interest in the future to establish the prognosis of this subgroup and whether these traits moderate the response to standard treatment, as suggested by Crane et al. [51]. 


\section{Abbreviations}

AN: Anorexia Nervosa; AQ: Autism Quotient; ASD: Autism Spectrum Disorder; BMI: Body Mass Index; BN: Bulimia Nervosa; CIA: Clinical Impairment Assessment; CY-BOCS-SR: Children's Yale-Brown Obsessive-Compulsive Scale Self-Report; DASS: Depression Anxiety Stress Scales; DAWBA: Development and Well-being Assessment; DSM-IV: Diagnostic and Statistical Manual of Mental Disorders; ED: Eating Disorder; I: Informant; ICD-10: International Statistical Classification of Diseases and Related Health Problems;

OCD: Obsessive-Compulsive Disorder; OCl-R: Obsessive-Compulsive Inventory Revised; SAS: Social Aptitude Scale; SD: Standard Deviation; SDQ: Strengths and Difficulties Questionnaire; SEED: Short Examination of Eating Disorders; SR: Self-Report.

\section{Competing interests}

The authors declare that they have no competing interests.

\section{Authors' contributions}

CR was a project coordinator for the Experienced Carers Helping Others $(\mathrm{ECHO})$ study and carried out data collection, statistical analysis and drafted the manuscript. EB prepared data for analysis. RH was a project coordinator for $\mathrm{ECHO}$, involved in the setup of the ECHO study, carried out data collection and critical appraisal of the manuscript content. EG, PM, SG, and US were involved in the design and setup of the study and contributed to the interpretation of data and critical appraisal of the manuscript content. SG was also Principal Investigator at one of the study recruitment sites. KT contributed to the interpretation of data and critical appraisal of the manuscript content. NM conducted the Development and Well-being Assessment clinician ratings, supervised statistical analysis, contributed to interpretation of data and was involved in revising the manuscript critically for important intellectual content. JT conceived of the study, participated in its design and coordination, contributed to the interpretation of results, and was involved in drafting of the manuscript and revising it critically for important intellectual content. All authors read and approved the final manuscript.

\section{Acknowledgements}

We thank Professor Robert Goodman for his guidance and support throughout this study.

This manuscript presents independent research funded by the National Institute for Health Research (NIHR) under its Research for Patient Benefit program (PB-PG-0609-19025). The views expressed in this article are those of the authors and not necessarily those of the NHS, the NIHR or the Department of Health. CR acknowledges scholarship funding from the Psychiatry Research Trust (PRT Grant Reference: 29). This study was supported by the United Kingdom Clinical Research Collaboration-registered King's Clinical Trials Unit at King's Health Partners, which is part funded by the NIHR Biomedical Research Centre for Mental Health at South London and Maudsley NHS Foundation Trust and King's College London and the NIHR Evaluation, Trials and Studies Coordinating Centre.

We also thank the Principal Investigators, who were involved in the recruitment of participants at the outpatient sites, listed alongside the site-specific ethical bodies who approved the study as follows: S Clark-Stone, 2gether NHS Foundation Trust; W Clarke, Anuerin Bevan Local Health Board; D Robertson, Birmingham and Solihull Mental Health NHS Foundation Trust; N Dawson, Bradford District Care Trust; C Schrieber-Kounine, Avon and Wiltshire Mental Health Partnership NHS Trust; J Shapleske, Cambridgeshire and Peterborough NHS Foundation Trust; J Whittaker, Central Manchester University Hospitals NHS Foundation Trust; A Jones, Cornwall Partnership NHS Trust; K Goss, Coventry and Warwickshire Partnership NHS Trust; H Crowson, Derbyshire Mental Health Services NHS Trust; K. Higgins, Dudley and Walsall Mental Health NHS Trust; N Green, Humber Mental Health Teaching NHS Trust; A Lodwick, Hywel dda Health Board; N Jacobs, Kent and Medway NHS and Social Care Partnership Trust; C Newell, Kimmeridge Court, Dorset Healthcare University NHS Foundation Trust; J Morgan, Leeds Partnership NHS Foundation Trust and St George's University of London; J Arcelus, Leicestershire Partnership NHS Trust; H Birchall, Lincolnshire Partnership NHS Foundation Trust; R Thompson, Norfolk and Waveney Mental Health Foundation Trust; H Stephens, North Bristol NHS Trust; I Lea, North Essex Partnership Foundation NHS Trust; L Addicott, Nottinghamshire Healthcare NHS Trust; S Sankar, Northamptonshire Healthcare NHS Trust; J Holliday, Oxford Health NHS Foundation Trust; B Waites, Powys Local Health
Board; H Strachan, Royal Bolton Hospital; A Fennell, Black Country Partnership NHS Foundation Trust; A Wolton, Somerset Partnership NHS Foundation Trust; H Gahan, South Essex Partnership University NHS Foundation Trust; G Moss, Sheffield Children's Hospital; J Orme, Sheffield Health and Social Care NHS Foundation Trust; K Moore, South Staffordshire and Shropshire Healthcare NHS Foundation Trust; G Burgoyne, Suffolk Mental Health Partnership NHS Trust; I. Eisler, South London and Maudsley NHS Foundation Trust; B Bamford, South-West London and St George's Mental Health Trust; I Yi, Surrey and Borders Partnership NHS Foundation Trust; and P Parker, Worcestershire Mental Health Partnership NHS Trust.

\section{Author details}

'King's College London, Institute of Psychiatry, Psychology and Neuroscience, Department of Psychological Medicine, Section of Eating Disorders, PO59 103 Denmark Hill, London SE5 8AF, UK. ${ }^{2}$ Department of Public Health and Community Medicine, University of Verona, P.le L.A. Scuro 10, Verona 37134, Italy. ${ }^{3}$ University of Liverpool, Psychological Sciences, Waterhouse Building, Block B, Brownlow Street, Liverpool L69 3GL, UK. ${ }^{4}$ llia State University, Kakutsa Cholokashvili Ave 3/5, Tbilisi 0162, Georgia. Institute of Child Health, Behavioral and Brain Sciences Unit, University College London, 30 Guilford Street, London WC1N 1EH, UK.

Received: 27 August 2014 Accepted: 20 November 2014

Published: 20 December 2014

\section{References}

1. Gillberg CL: The Emanuel Miller Memorial Lecture, Autism and autistic-like conditions: subclasses among disorders of empathy. J Child Psychol Psychiatry 1991, 1992(33):813-842.

2. Zucker NL, Losh M, Bulik CM, LaBar KS, Piven J, Pelphrey KA: Anorexia nervosa and autism spectrum disorders: guided investigation of social cognitive endophenotypes. Psychol Bull 2007, 133:976-1006.

3. Treasure J: Coherence and other autistic spectrum traits and eating disorders: building from mechanism to treatment. The Birgit Olsson lecture. Nord J Psychiatry 2013, 67:38-42.

4. Oldershaw A, Hambrook D, Stahl D, Tchanturia K, Treasure J, Schmidt U: The socio-emotional processing stream in Anorexia Nervosa. Neurosci Biobehav Rev 2011, 35:970-988.

5. Lang K, Stahl D, Espie J, Treasure J, Tchanturia K: Set shifting in children and adolescents with anorexia nervosa: an exploratory systematic review and meta-analysis. Int J Eat Disord 2014, 47:394-399.

6. Huke V, Turk J, Kent A, Morgan JF: Autism spectrum disorders in eating disorder populations: a systematic review. Eur Eat Disord Rev 2013, 21:345-351.

7. Hambrook D, Tchanturia K, Schmidt U, Russell T, Treasure J: Empathy, systemizing, and autistic traits in anorexia nervosa: a pilot study. $\mathrm{Br} J$ Clin Psychol 2008, 47:335-339.

8. Baron-Cohen S, Jaffa T, Davies S, Auyeung B, Allison C, Wheelwright S: Do girls with anorexia nervosa have elevated autistic traits? Mol Autism 2013, 4:24.

9. Tchanturia K, Smith E, Weineck F, Fidanboylu E, Kern N, Treasure J, Baron-Cohen S: Exploring autistic traits in anorexia: a clinical study. Mol Autism 2013, 4:44.

10. Råstam $M$, Täljemark J, Tajnia A, Lundström S, Gustafsson P, Lichtenstein $P$, Gillberg C, Anckarsäter H, Kerekes N: Eating problems and overlap with ADHD and autism spectrum disorders in a nationwide twin study of 9- and 12-year-old children. Sci World J 2013, 2013:315429.

11. Kirkovski M, Enticott PG, Fitzgerald PB: A review of the role of female gender in autism spectrum disorders. J Autism Dev Disord 2013, 43:2584-2603.

12. Kopp S, Gillberg C: The Autism Spectrum Screening Questionnaire (ASSQ)-Revised Extended Version (ASSQ-REV): an instrument for better capturing the autism phenotype in girls? A preliminary study involving 191 clinical cases and community controls. Res Dev Disabil 2011, 32:2875-2888.

13. Lai MC, Lombardo MV, Pasco G, Ruigrok ANV, Wheelwright SJ, Sadek SA, Chakrabarti B, Baron-Cohen S: A behavioral comparison of male and female adults with high functioning autism spectrum conditions. PLoS One 2011, 6:e20835.

14. Lilenfeld LR, Kaye WH, Greeno CG, Merikangas KR, Plotnicov K, Pollice C, Rao R, Strober M, Bulik CM, Nagy L: A controlled family study of anorexia nervosa 
and bulimia nervosa: psychiatric disorders in first-degree relatives and effects of proband comorbidity. Arch Gen Psychiatry 1998, 55:603-610.

15. Anderluh MB, Tchanturia K, Rabe-Hesketh S, Treasure J: Childhood obsessive-compulsive personality traits in adult women with eating disorders: defining a broader eating disorder phenotype. Am J Psychiatr 2003, 160:242-247.

16. Lang K, Lopez C, Stahl D, Tchanturia K, Treasure J: Central coherence in eating disorders: an updated systematic review and meta-analysis. World J Biol Psychiatry 2014, 1:1-13.

17. Happé FGE, Booth RDL: The power of the positive: revisiting weak coherence in autism spectrum disorders. Q J Exp Psychol 2008, 61:50-63.

18. Savage CR, Deckersbach T, Wilhelm S, Rauch SL, Baer L, Reid T, Jenike MA: Strategic processing and episodic memory impairment in obsessive compulsive disorder. Neuropsychology 2000, 14:141-151.

19. Montigny C, Castellanos-Ryan N, Whelan R, Banaschewski T, Barker GJ, Büche C, Gallinat J, Flor H, Mann K, Paillère-Martinot ML, Nees F, Lathrop M, Loth E, Paus T, Pausova Z, Rietsche M, Schumann G, Smolka MN, Struve M, Robbins TW, Garavan H, Conrod PJ: A phenotypic structure and neural correlates of compulsive behaviors in adolescents. PLoS One 2013, 8:e80151.

20. Goodman R, Ford T, Richards H, Gatward R, Meltzer H: The development and well-being assessment: description and initial validation of an integrated assessement of child and adolescent psychopathology. J Child Psychol Psychiat Allied Discip 2000, 41:645-655.

21. American Psychiatric Association (APA): Diagnostic and Statistical Manual of Mental Disorders 4th edition (DSM-IV). Washington DC: Author; 1994

22. Keverne EB: Understanding well-being in the evolutionary context of brain development. Phil Trans R Soc B Biol Sci 2004, 359:1349-1358.

23. Schmidt U, Lee S, Beecham J, Perkins S, Treasure J, Yi I, Winn S, Robinson P, Murphy R, Keville S, Johnson-Sabine E, Jenkins M, Frost S, Dodge L, Berelowitz $M$, Eisler I: A randomized controlled trial of family therapy and cognitive behavior therapy guided self-care for adolescents with bulimia nervosa and related disorders. Am J Psychiatr 2007, 164:591-598.

24. Rhind C, Hibbs R, Goddard E, Schmidt U, Micali N, Gowers S, Beecham J, Macdonald P, Todd G, Tchanturia K, Treasure J: Experienced Carers Helping Others (ECHO): protocol for a pilot randomised controlled trial to examine a psycho-educational intervention for adolescents with anorexia nervosa and their carers. Eur Eat Disord Rev 2014, 22:267-277.

25. Fombonne E, Simmons H, Ford T, Meltzer H, Goodman R: Prevalence of pervasive developmental disorders in the British nationwide survey of child mental health. J Am Acad Child Adolesc Psychiatry 2001, 40:820-827.

26. Heiervang E, Stormark KM, Lundervold AJ, Heimann M, Goodman R, Posserud MB, Ullebø AK, Plessen KJ, Bjelland I, Lie SA, Gillberg C: Psychiatric disorders in Norwegian 8- to 10-year-olds: an epidemiological survey of prevalence, risk factors, and service use. J Am Acad Child Adolesc Psychiatry 2007, 46:438-447.

27. Liddle EB, Batty MJ, Goodman R: The social aptitudes scale: an initial validation. Soc Psychiatry Psychiatr Epidemiol 2009, 44:508-513.

28. Goodman R: Psychometric properties of the strengths and difficulties questionnaire. J Am Acad Child Adolesc Psychiatry 2001, 40:1337-1345.

29. Meltzer H, Gatward R, Goodman R, Ford T: Mental Health of Children and Adolescents in Great Britain. London: The Stationery Office; 2000.

30. Scahill L, Riddle M, McSwiggin-Hardin M, Ort S, King I, Goodman R: Children's Yale-brown obsessive-compulsive scale: reliability and validity. J Am Acad Child Adolesc Psychiatry 1997, 36:844-852.

31. Bauer S, Winn S, Schmidt U, Kordy H: Construction, scoring and validation of the Short Evaluation of Eating Disorders (SEED). Eur Eat Disord Rev 2005, 13:191-200.

32. Bohn K, Fairburn C: The Clinical Impairment Assessment Questionnaire (CIA), in Cognitive Behaviour Therapy and Eating Disorders. New York: Guildford Press; 2008.

33. Lovibond PF, Lovibond SH: The structure of negative emotional states: comparison of the depression anxiety stress scales (DASS) with the Beck Depression and Anxiety Inventories. Behav Res Ther 1995, 33:335-343.

34. Allison C, Auyeung B, Baron-Cohen S: Toward brief "red flags" for autism screening: the short Autism Spectrum Quotient and the short Quantitative Checklist in 1,000 cases and 3,000 controls. J Am Acad Child AdolesC Psychiatry 2012, 51:202-212.

35. Foa EB, Huppert JD, Leiberg S, Langner R, Kichic R, Hajcak G, Salkovskis PM: The obsessive-compulsive inventory: development and validation of a short version. Psychol Assess 2002, 14:485-496.
36. Wentz E, Lacey JH, Waller G, Råstam M, Turk J, Gillberg C: Childhood onset neuropsychiatric disorders in adult eating disorder patients. A pilot study. Eur Child Adolesc Psychiatry 2005, 14:431-437.

37. Wentz E, Gillberg IC, Anckarsäter H, Gillberg C, Råstam M: Adolescent-onset anorexia nervosa: 18-year outcome. Br J Psychiatry 2009, 194:168-174.

38. Krug I, Penelo E, Fernandez-Aranda F, Anderluh M, Bellodi L, Cellini E, Di Bernardo M, Granero R, Karwautz A, Nacmias B, Ricca V, Sorbi S, Tchanturia K, Wagner G, Collier D, Treasure J: Low social interactions in eating disorder patients in childhood and adulthood: a multi-centre European case control study. J Health Psychol 2012, 18:26-37.

39. Allen $\mathrm{KL}$, Byrne SM, Forbes D, Oddy WH: Risk factors for full- and partial-syndrome early adolescent eating disorders: a population-based pregnancy cohort study. J Am Acad Child Adolesc Psychiatry 2009, 48:800-809.

40. Caglar-Nazali HP, Corfield F, Valentina C, Ambwani S, Lappanen J, Olabintan O, Deriziotis S, Hadjimichalis A, Scognamiglio P, Eshkevari E, Micali N, Treasure J: A systematic review and meta-analysis of 'Systems for Social Processes' in eating disorders. Neurosci Biobehav Rev 2013, 42:55-92.

41. Hughes EK, Goldschmidt AB, Labuschagne Z, Loeb KL, Sawyer SM, Grange DL: Eating disorders with and without comorbid depression and anxiety: similarities and differences in a clinical sample of children and adolescents. Eur Eat Disord Rev 2013, 21:386-394.

42. Serpell L, Hirani V, Willoughby K, Neiderman M, Lask B: Personality or pathology?: obsessive-compulsive symptoms in children and adolescents with anorexia nervosa. Eur Eat Disord Rev 2006, 14:404-413.

43. Nazar BP, Pinna CMDS, Coutinho G, Segenreich D, Duchesne M, Appolinario JC, Mattos P: Review of literature of attention-deficit/hyperactivity disorder with comorbid eating disorders. Rev Bras Psiquiatr 2008, 30:384-389.

44. Mohammadi MR, Zarafshan H, Ghasempour S: Broader autism phenotype in iranian parents of children with autism spectrum disorders vs. Normal children. Iran J Psychiatry 2012, 7:157-163.

45. Ruta L, Mazzone D, Mazzone L, Wheelwright S, Baron-Cohen S: The autism-spectrum quotient-Italian version: a cross-cultural confirmation of the broader autism phenotype. J Autism Dev Disord 2012, 42:625-633.

46. Kose S, Bora E, Eremis S, Özbaran B, Bildik TM, Aydin C: Broader autistic phenotype in parents of children with autism: autism spectrum quotient-Turkish version. Psychiatry Clin Neurosci 2013, 67:20-27.

47. Bishop DV, Maybery M, Maley A, Wong D, Hill W, Hallmayer J: Using self-report to identify the broad phenotype in parents of children with autistic spectrum disorders: a study using the Autism-Spectrum Quotient. J Child Psychol Psychiatry 2004, 45:1431-1436.

48. Lau WY, Gau SS, Chiu YN, Wu YY, Chou WJ, Liu SK, Chou MC: Psychometric properties of the Chinese version of the Autism Spectrum Quotient (AQ). Res Dev Disabil 2013, 34:294-305.

49. Eisenberg N, Fabes RA, Guthrie IK, Reiser M: Dispositional emotionality and regulation: their role in predicting quality of social functioning. $J$ Pers Soc Psychol 2000, 78:136-157.

50. Robbins TW, Gillan CM, Smith DG, de Wit S, Ersche KD: Neurocognitive endophenotypes of impulsivity and compulsivity: Towards dimensional psychiatry. Trends Cogn Sci 2011, 16:81-91.

51. Crane AM, Roberts ME, Treasure J: Are obsessive-compulsive personality traits associated with a poor outcome in anorexia nervosa? A systematic review of randomized controlled trials and naturalistic outcome studies. Int J Eat Disord 2007, 40:581-8.

doi:10.1186/2040-2392-5-56

Cite this article as: Rhind et al: An examination of autism spectrum traits in adolescents with anorexia nervosa and their parents. Molecular Autism 2014 5:56. 